\title{
Chemometric analysis for pollution source identification and human health risk assessment of water resources in Ojoto Province, southeast Nigeria
}

\author{
Johnbosco C. Egbueri ${ }^{1}\left[\right.$ (D) Chukwuma N. Mgbenu² ${ }^{\mathbb{D}}$
}

Received: 19 August 2019 / Accepted: 16 March 2020 / Published online: 23 March 2020

(c) The Author(s) 2020

\begin{abstract}
This paper quantified the level of heavy metals contamination, identified possible sources of pollution, and assessed the human health risks associated with drinking water resources in Ojoto Province, Nigeria. The study's gross findings revealed that the suitability of some water sources for consumption purposes in this province is questionable. Based on water quality index, $57.14 \%$ of the total samples are within acceptable limits, while $42.86 \%$ are unsuitable for drinking. It was observed that the northwestern and southern parts of the study area have more of deteriorated water quality. The health hazard index revealed that $25 \%$ of the samples predispose their consumers (both adult and children populations) to high chronic health risks. Moreover, heavy metal pollution index, contamination index, and probability of cancer risk (CR) revealed that about $25 \%$ of the total samples were unsuitable and off the CR standard acceptable range of $\leq 1 \times 10^{-6}-1 \times 10^{-4}$. Correlation and component factor analyses linked the origin of major ions to geogenic processes and that of the heavy metals to both natural and anthropogenic processes. Cluster analysis divided the samples into two equal classes (50\% each): poor and excellent quality waters. This study indicated that $\mathrm{Pb}$ is the priority pollutant impacting the water quality. The various assessments revealed that waters from hand-dug wells and deeper boreholes are the least contaminated and hence best suited for drinking than waters from springs, streams, and shallow wells.
\end{abstract}

Keywords Carcinogenic health risk assessment $\cdot$ Heavy metal contamination $\cdot$ Non-carcinogenic health risk assessment . Pollution indices $\cdot$ Risk factor $\cdot$ Water quality assessment

\section{Introduction}

Quality and safe drinking water is essential for the sustainability of human health and the environment. Contamination of drinking water supplies poses a lot of threats to humans and the environment. Usually, the deterioration in water quality is due to organic and inorganic contaminations. Inorganic contaminants include chemical ions and trace (heavy) metals such as $\mathrm{Pb}, \mathrm{Ni}$, and $\mathrm{Cr}$. These trace metals are among the most hazardous water contaminants because they have peculiar characteristics which include chemical stability,

Johnbosco C. Egbueri

johnboscoegbueri@gmail.com; jc.egbueri@coou.edu.ng

1 Department of Geology, Chukwuemeka Odumegwu Ojukwu University, Uli, Nigeria

2 Department of Physics/Geology/Geophysics, Federal University, Ndufu-Alike, Ikwo, Nigeria weak degradation (decomposition), wide range of sources, high toxicity, bioaccumulation and remediation difficulties (Sun et al. 2016; Barzegar et al. 2018). Heavy metals contamination in water systems has been noted to be a worrisome problem worldwide due to growing population and economic development.

According to US Environmental Protection Agency (USEPA 2011, 2017), a population's exposure to heavy metals in water can occur by direct ingestion (through drinking) or indirect ingestion (through use in foods and drinks made with contaminated water). However, incidental ingestion (maybe, swallowing water while swimming), dermal contact (during showering or bathing), or inhalation (inhaling vapors during showering) can also occur (US-EPA 2011, 2017). All over the world, the consumption (ingestion) of heavy metals-contaminated waters has been reported to cause serious health issues (disasters) like skin, lung, and bladder cancers; bronchiectasis; intellectual disabilities; neurological, cardiovascular, kidney, and bone diseases; hyperpigmentation of

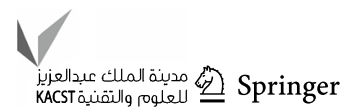


the palm and sole; hypertension; myocardial damage; liver damage; Bowens disease; diabetes, etc. (Rahman et al. 2017; Sridharan and Nathan 2018; Mgbenu and Egbueri 2019; Ukah et al. 2019; Egbueri 2019c, 2020a).

These trace elements enter water systems through many natural processes and anthropogenic activities (Wagh et al. 2018; Barzegar et al. 2018; Egbueri 2018, 2019a, b; Ezugwu et al. 2019; Mgbenu and Egbueri 2019). The natural processes that contribute to high concentration of heavy metals in waters include weathering of rocks and soils, decomposition of living matter, and atmospheric fall-out, whereas the anthropogenic activities encompass mining (which can lead to acid mine drainage) and mineral processing, domestic, agricultural and industrial wastes, etc. Furthermore, studies have shown that heavy metal pollution in water resources is also attributed to many other anthropogenic factors, including the overuse of chemical fertilizers and pesticides, untreated industrial wastes, poor management of open dumpsites, etc. (Bhuiyan et al. 2010; Belkhiri et al. 2017; Egbueri 2018, 2019a, b, 2020a, b; Ukah et al. 2019). When these various processes release trace elements into water systems, another important factor that determines the impact such metals have on the quality of water is solubility. Musa et al. (2013) and Wagh et al. (2018) reported that solubility of trace metals in soils and waters is mainly governed by $\mathrm{pH}$, metal concentration, organic carbon concentration, ion exchange capacity, the oxidation state of mineral constituents, and redox potential of the media (soils or waters).

Knowledge of the contents of trace elements in water and their associated health impacts is imperative for effective water resource monitoring, management, and sustainability. Therefore, human health risk analysis is an important tool toward actualizing these goals. Health risk assessment of water resources measures and quantifies the potential impact of water pollution on human health based on water quality standards and health risk benchmarks (Zhu et al. 2017; Egbueri 2020a). Risk assessment is aimed at minimizing the health risks associated with consuming contaminated drinking water by a host of techniques (US-EPA 1999, 2011; Zhu et al. 2017). This assessment is often carried out using chemometrics, which basically employs mathematical or statistical principles in solving problems linked to chemical water pollution. In different parts of the world, researchers (Belkhiri et al. 2017; Njinga and Tshivhase 2017; Rahman et al. 2017; Barzegar et al. 2018; Wagh et al. 2018; Mgbenu and Egbueri 2019) have successfully used different mathematical and statistical methodologies to assess the health risks of various water supplies. Such methodologies include pollution indices, multivariate statistical analyses, carcinogenic and non-carcinogenic health risk analyses. Moreover, various geostatistical tools (such as ordinary kriging and semi-variogram models) and geospatial tools can also be employed in attempt to classify water quality and health risks associated with contaminated water resources (Rahman et al. 2017).

In Ojoto Province, different water sources, such as springs, streams, hand-dug wells, and boreholes, are used by residents for various domestic purposes, including drinking and cooking. However, no previous literature seems to have assessed health risks associated with the use of these water supplies. The possible health impacts of the heavy metals in the waters of Ojoto Province have not been reported previously. Therefore, this present study attempts to employ chemometrics in assessing the various human health risks associated with the use of the water resources in the study area. The study objectives were to (1) identify and measure inorganic ions (such as $\mathrm{Na}, \mathrm{Cl}, \mathrm{Ca}, \mathrm{SO}_{4}, \mathrm{NO}_{3}$, and $\mathrm{HCO}_{3}$ ) and trace elements (such as $\mathrm{Fe}, \mathrm{Zn}, \mathrm{Pb}, \mathrm{Ni}$, and $\mathrm{Cr}$ ) in the waters; (2) determine heavy metal pollution levels and indices in the study area; (3) assess and classify the potential human health (carcinogenic and non-carcinogenic) risks of these elements to children and adult populations through ingestion; and (4) identify, using chemometric analytical tools, the interrelationships between water quality and health risk parameters and their source apportionment in the drinking water resources. Basically, the major focus of this paper is on heavy metals $(\mathrm{Fe}, \mathrm{Zn}, \mathrm{Ni}, \mathrm{Cr}$, and $\mathrm{Pb}$ ) contamination. These heavy metals were chosen for the study with regard to the dominant human activities and land use pattern, which were thought could release them into the sampled water systems, in the Ojoto Province. It is expected that this work will provide insights needful in the monitoring, management, and sustainability of the water resources for human health and the environment in Ojoto Province, southeastern Nigeria.

\section{Study area description}

Ojoto area is a suburban which lies within latitudes $06^{\circ} 00^{\prime}$ $\mathrm{N}-6^{\circ} 05^{\prime} \mathrm{N}$ and longitudes $06^{\circ} 50^{\prime} \mathrm{E}-07^{\circ} 00^{\prime} \mathrm{E}$ (Fig. 1). The study area is about $15 \mathrm{~km}$ southeast of Onitsha, a very big and important commercial city in the West Africa. Some businesspeople and industrialists in Onitsha city now settle in Ojoto Province, thereby influencing its population growth. Topographically, the study area is resting on top of gentle dipping parts of the Awka-Orlu Ridge. Peak elevations are attained toward the eastern parts of the area. In other parts, elevation drops rapidly and the rivers Obibia and Odoh (not shown on the map in Fig. 1) intensely reduce the landscape to badlands, rills, and gullies of diverse sizes and shapes. The surface water networks in the area ultimately pay tributes to the large River Niger, westward of the study area. The rills and gullies in the study area are commonly used as open waste dumpsites.

Wet/rainy season (which roughly spans from April to November) and dry season (that lasts for about 4 months, 


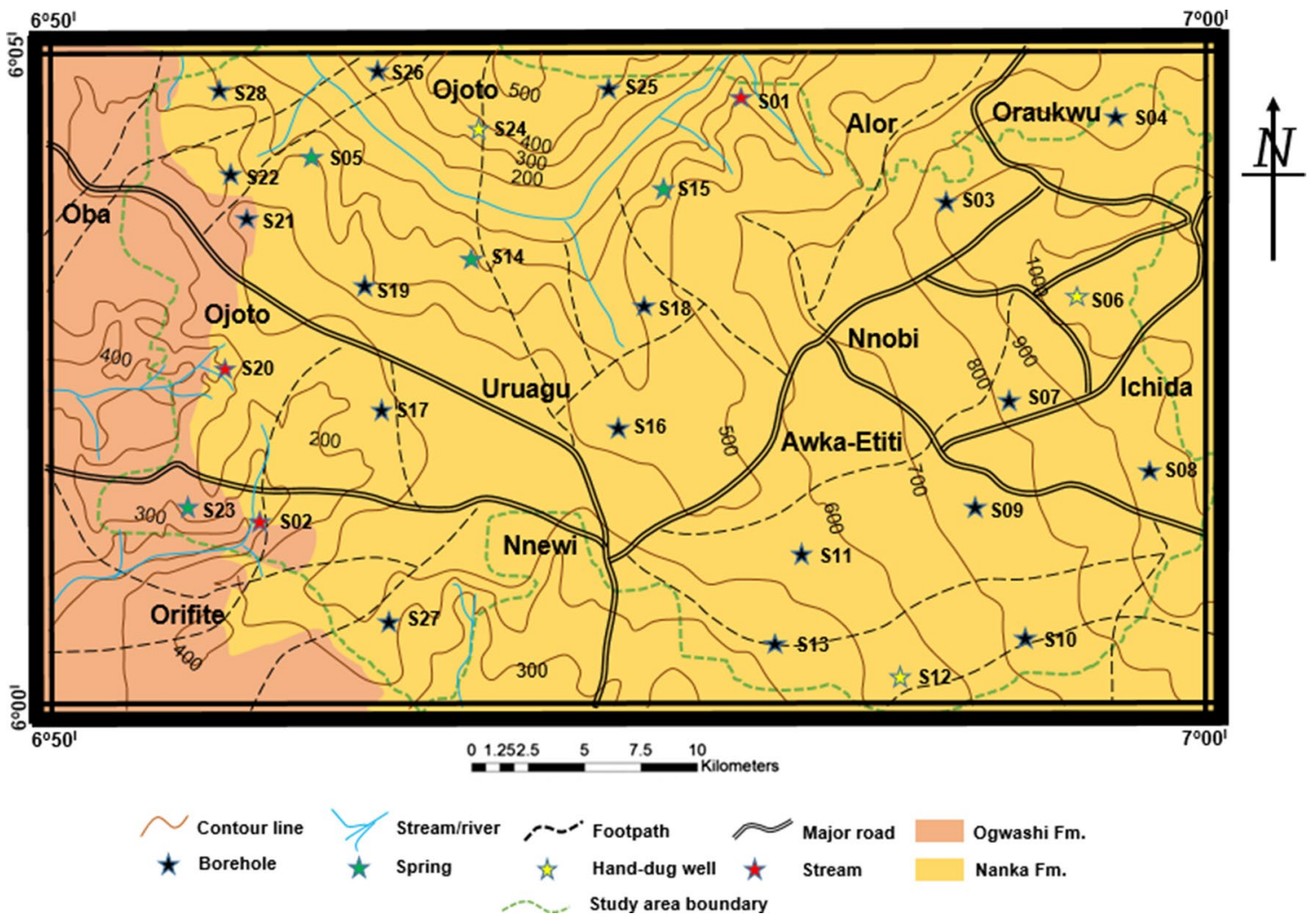

Fig. 1 Location and geologic map showing the study area

usually from December to March) are the two distinct seasons that characterize the study area. The two seasons are attributed, respectively, to the southwest trade winds from the Atlantics and the northeastern wind blowing across the Sahara. Because of the location of the area, it receives constant insolation all through the year. During the dry seasons, temperatures reach as high as $32{ }^{\circ} \mathrm{C}$, while average relative humidity sometimes drops to as low as $20 \%$. Annual rainfall in the area varies from about 1500 to $2000 \mathrm{~mm}$ in rainy seasons, with the driest month (in the dry season) usually recording less than $30 \mathrm{~mm}$ of precipitation (Nwajide 2013).

The Eocene Nanka Sandstone and the Oligocene-Miocene Ogwashi Formation are two major geologic formations underlying the study area (Fig. 1; Egbueri et al. 2019). The regressive deposits of the Nanka Formation (Nwajide 2013) comprise the later portions of the second phase (Campanian-Eocene) of compressive movements which were instrumental in the folding of the Abakaliki Anticlinorium (Nwachukwu 1972). The third phase of that tectonic movement is thought to have commenced toward the end of the Eocene, depositing the Ogwashi Formation and shifting the depocenters downward to form the Niger Delta (Obi et al. 2001). The Nanka Formation, which is composed of alternating friable sand, shale, sandy shale, and fine-grained fossiliferous sandstone intervals with some thin bands of limestone and ironstones, covers over $80 \%$ of the study area and spans the central and eastern portions (Reyment 1965, Arua 1986, Nwajide 2013). Contrarily, the Ogwashi Formation, which overlies the Nanka Sandstone, comprises an alternation of coarse-grained sandstone, ironstones, light-colored mudrocks, and lignite seams (Kogbe 1976, Nwajide 2013).

Previous researches reported that the Ogwashi and Nanka formations are prolific aquiferous geologic units with varying aquifer depths (Nfor et al. 2007; Okoro et al. 2010a, b; Akpoborie et al. 2011). Studies by Okoro et al. (2010a, b) reported various aquifer properties, including hydraulic conductivity, transmissivity, and pumping test estimates, of the Nanka Formation. According to Nfor et al. (2007), the Nanka Formation generally has its aquiferous layers at depths $\geq 20 \mathrm{~m}$, whereas Okoro et al. (2010b) reported that the aquiferous layers are at depths of $\geq 7 \mathrm{~m}$. However, Akpoborie et al. (2011) delineated two major aquifer systems in the Ogwashi Formation. According to them, the first is an alluvial terrace deposit which is shallow (at about the range of 30-80 m) and most preferred by borehole drillers, while the second is encountered at greater depths (about $110-180 \mathrm{~m}$ ) and is composed of iron-rich water (Akpoborie et al. 2011). However, Nfor et al. (2007) reported that three aquifer units characterize the Ogwashi Formation: first unit

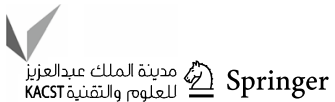


at depth range of 30-50 m, second unit at 70-90 m, and third unit at $140-169 \mathrm{~m}$.

Commerce, agriculture, and industry are the main land use activities in the study area. Commerce activities include the buying and selling of auto spare parts, plumbing materials, plastics, agricultural products, and basic commodities for homes. Agricultural activities include the use of fertilizers and livestock farming, etc. Industrial activities, which are relatively intense, include water industry, food processing, and petrochemical production, etc. Due to the dominant land use pattern and the presence of many mechanic workshops in the study area, large amount of wastes is generated on daily basis. However, these wastes are indiscriminately disposed on soils, surface water bodies (which are most important sources for the recharge of the aquifers in the area), and in open waste dumpsites. In the study area, springs, streams, hand-dug wells, and boreholes are extensively used as primary sources of drinking water for different populations. Nevertheless, the poor waste disposal by commercial, domestic, industrial, and agricultural activities exposes these drinking water sources to contamination.

\section{Materials and methods}

\section{Water sampling and sample analysis}

A total of 28 water samples were analyzed to achieve the aim of this study. The samples included those collected from springs (5 samples), streams (3 samples), hand-dug wells ( 3 samples), and boreholes (17 samples) in dry season. This study employed random sampling method across the study area. For water sample collection, 1-L polythene bottles washed with distilled water were used. Stream samples were collected about 1-2 m away from stream banks. Spring samples were collected directly from spring head (i.e., from the rock sourcing the water). Depths of hand-dug wells ranged from about 7 to $11 \mathrm{~m}$. Reports by Nfor et al. (2007) and Okoro et al. (2010b) placed the depths of the boreholes within the Nanka Formation of the study region in the range of $\geq 20$ and $\geq 7 \mathrm{~m}$, respectively. However, Nfor et al. (2007) reported the aquifer depths of Ogwashi Formation to be in the range of 30-169 m, while Akpoborie et al. (2011) reported the depths to be at around $30-80 \mathrm{~m}$ for shallow aquifer and 110-180 $\mathrm{m}$ for deeper aquifer. Locations of the sampling points are illustrated in Fig. 1. Boreholes were pumped for a minimum of $20 \mathrm{~min}$ prior to collection of samples to ensure that the water was fresh. At each sampling point, the water to be sampled was used to rinse the sample bottle several times before sample collection. After sampling, the samples were acidified with $1 \mathrm{~mL}$ concentrated nitric acid $\left(\mathrm{HNO}_{3}\right)$ to prevent precipitation of cations.
The $\mathrm{pH}$ was measured in situ using a $\mathrm{pH}$ meter (Testr-2). To reduce the growth of microbes and algae and other inorganic reactivity in the collected samples, they were analyzed within $48 \mathrm{~h}$ of samples collection. Standard testing methods, as recommended by American Public Health Association (APHA 2005), were employed for chemical ions and heavy metal analyses. Prior to the analysis of the chemical constituents, the water samples were filtered through cellulose acetate filter (0.45-micron millipore filter). The filter was washed with deionized water before filtration. Flame photometer (Model: Systronics Flame Photometer 128) was used for analysis of $\mathrm{Na}$, while titration method was employed in assessing major and minor ions such as $\mathrm{Cl}, \mathrm{Ca}$, and $\mathrm{HCO}_{3}$. $\mathrm{NO}_{3}$ and $\mathrm{SO}_{4}$ were analyzed by spectrophotometry. All the heavy metals $(\mathrm{Fe}, \mathrm{Zn}, \mathrm{Cr}, \mathrm{Ni}$, and $\mathrm{Pb}$ ) were analyzed using the Atomic Absorption Spectrophotometer (AAS) technique (Bulk Scientific 210 VGP).

\section{Water quality indexing (WQI)}

WQI reveals the multivariate composite influence of individual water quality parameters on the overall quality of water resources for drinking purposes (Rahman et al. 2017; Mgbenu and Egbueri 2019; Ukah et al. 2019). Using weighted arithmetic quality indexing method, the WQI was calculated to assess the suitability of the various water supplies in Ojoto for drinking purposes. This was done with respect to the $\mathrm{pH}$ and heavy metals in the waters. In other words, this method classified the water quality of Ojoto according to the degree of purity by calculating the quality index using $\mathrm{pH}$ and the analyzed heavy metals used in the health risk assessment. Specific weights $\left(w_{i}\right)$ were assigned to the selected parameters, based on their individual significance in water quality analysis (Egbueri et al. 2019; Mgbenu and Egbueri 2019; Egbueri 2020a). The mathematical formula used in calculating the WQI is given as:

$\mathrm{WQI}=\sum \mathrm{SI}_{i-n}$

where SI is the subquality index of $i$ th variables. The SI is obtained using Eq. (2).

$\mathrm{SI}_{i}=W_{i} \times Q_{i}$

where $W_{i}$ is the relative weight unit of each variable, and $Q_{i}$ is the quality rating of each of the variables used in the WQI analysis. The $W_{i}$ was calculated using Eq. (3), while the $Q_{i}$ was obtained using Eq. (4).

$W_{i}=w_{i} / \sum_{i=1}^{n} w_{i}$ 
$Q_{i}=\left(C_{i} / S_{i}\right) \times 100$

where $w_{i}$ is the assigned specific weight of parameter; $n$ is the number of parameters; $C_{i}$ is concentration of each parameter in $\mathrm{mg} / \mathrm{L}$; and $S_{i}$ is permissible limit of the Nigerian Industrial Standard (NIS 2007) in $\mathrm{mg} / \mathrm{L}$. The waters were later classified based on the WQI classification scheme reported in Mgbenu and Egbueri (2019): WQI $<50=$ excellent water; $50-100=$ good water; $100-200=$ poor water; $200-300=$ very poor water; and $>300=$ unfit for drinking.

\section{Non-carcinogenic health risk assessment}

The non-carcinogenic health risks of intake of trace elementcontaminated water by human (adults and children) population in undesirable quantities have been classified by different authors (Bortey-Sam et al. 2015; Duggal et al. 2017; Barzegar et al. 2018; Zhang et al. 2018; Ezugwu et al. 2019; Mgbenu and Egbueri 2019; Ukah et al. 2019; Egbueri 2020a).

\section{Chronic daily intake (CDI)}

Employing the guidelines presented by US-EPA (1989), the chronic daily intake (CDI) risks posed by ingesting a single trace element are computed for the children and adult populations as follows:

$\mathrm{CDI}=\frac{C_{\mathrm{W}} \times \mathrm{IRW} \times \mathrm{EF} \times \mathrm{ED}}{\mathrm{BW} \times \mathrm{AT}}$

where CDI is the chronic daily intake and otherwise referred to as the exposure dose (mg/kg/day); $C_{w}$ signifies the contaminant concentration in water $(\mathrm{mg} / \mathrm{L})$; IRW represents the water ingestion rate (IRW is equal to $1 \mathrm{~L}$ for children and $2 \mathrm{~L}$ for adults); $\mathrm{EF}$ is used to denote the exposure frequency (EF is equivalent to 365 days per year); ED signifies the exposure duration (adult $\mathrm{ED}=70$ years while children $\mathrm{ED}=6$ years); BW is the body weight (equivalent to $70 \mathrm{~kg}$ and $15 \mathrm{~kg}$ for adult and children, respectively); AT represents the average exposure time (equivalent to 25,550 days and 2190 days for adult and children, respectively) (Duggal et al. 2017; Barzegar et al. 2018; Mgbenu and Egbueri 2019; Egbueri 2020a).

\section{Hazard quotients (HQ)}

Using Eq. (6) the non-carcinogenic risk of a single element calculated as the hazard quotient is evaluated using the function:

$\mathrm{HQ}=\frac{\mathrm{CDI}}{\mathrm{RfD}}$ where RfD represents the reference dose of a specific element $(\mathrm{mg} / \mathrm{kg} /$ day). The RfD equivalent for the different trace elements is $0.0035(\mathrm{~Pb}), 0.7(\mathrm{Fe}), 0.3(\mathrm{Zn}), 1.5(\mathrm{Cr})$, and 0.02 (Ni) (Duggal et al. 2017; Barzegar et al. 2018; Zhang et al. 2018; Mgbenu and Egbueri 2019; Egbueri 2020a).

\section{Hazard index (HI)}

The final value for the non-carcinogenic risk assessment is the hazard index (HI), which is the summation of the hazard quotient values.

$\mathrm{HI}=\sum \mathrm{HQ}$

According to US-EPA (1989) and Su et al. (2017), if HI is greater than unity ( $\mathrm{HI}>1)$, it implies that the non-carcinogenic health risk of ingesting a particular element is above the acceptance limit, whereas $\mathrm{HI}<1$ implies that they are within the acceptance limit. Non-carcinogenic risk is, therefore, classified on the basis of $\mathrm{HI}$ values into negligible (risk level 1; $\mathrm{HI}<0.1$ ), low risk (risk level $2 ; \mathrm{HI} \geq 0.1<1$ ), medium risk (risk level 3; $\mathrm{HI} \geq 1<4$ ), and high risk (risk level 4; HI $\geq 4$ ) (Bortey-Sam et al. 2015; Mgbenu and Egbueri 2019; Egbueri 2020a).

\section{Carcinogenic health risk assessment}

\section{Heavy metal evaluation index (HEI)}

HEI is used in assessing associated carcinogenic risks of a given set of water samples. This is because it gives an overall quality of waters with respect to their heavy metals content (Edet and Offiong 2002; Wagh et al. 2018; Ezugwu et al. 2019; Ukah et al. 2019; Egbueri 2020a). HEI is, therefore, calculated using:

$\mathrm{HEI}=\sum_{i=1}^{n}{\frac{H_{c}}{H_{\mathrm{MAC}}}}$

where $H_{c}=$ monitored value; $H_{\mathrm{MAC}}=$ maximum admissible concentration (MAC) of the $i$ th parameter.

\section{Heavy metal pollution index (HPI)}

The HPI is also a risk assessment method that considers the composite effects of individual heavy metal on the overall water quality and suitability for drinking. Many researchers (Horton 1965; Brown et al. 1970; Edet and Offiong 2002; Odukoya and Abimbola 2010; Herojeet et al. 2015; Wagh et al. 2018; Egbueri 2018, 2020a) have successfully employed HPI extensively in determining the overall quality of water based on heavy metal concentrations. The NIS (2007) drinking water quality standards were used for the 
calculation of heavy metal indices of the various samples. In this study, the five trace metals were considered for calculation of HPI. The HPI is then calculated using the formula given in Eq. (9) (Odukoya and Abimbola 2010; Egbueri 2018, 2020a; Ezugwu et al. 2019; Ukah et al. 2019).

$\mathrm{HPI}=\frac{\mathrm{HMC}}{\mathrm{AL}} / n$

where $\mathrm{HMC}=$ heavy metal concentration in water sample; $\mathrm{AL}=$ allowable limit; and $n=$ number of analyzed heavy metals.

\section{Degree of contamination $\left(C_{\mathrm{deg}}\right)$}

In order to further analyze the quality of the water resources based on carcinogenic exposure and impact, the degree of contamination $\left(C_{\mathrm{deg}}\right)$ (also known as contamination index) was evaluated. $C_{\mathrm{deg}}$ is also used as a reference of estimating the extent of trace element pollution (Al-Ami et al. 1987). The $C_{\text {deg }}$ was computed using Eqs. (10 and (11) (Edet and Offiong 2002; Wagh et al. 2018; Egbueri 2020a):

$C_{\mathrm{deg}}=\sum_{i=1}^{n} C_{f_{i}}$

$C_{f i}=\frac{C_{A i}}{C_{N i}}-1$

where $C_{f i}=$ contamination factor for the $i$ th parameter; $C_{A i}=$ analytical value for the $i$ th component; and $C_{N i}=$ upper permissible concentration of the $i$ th parameter.

\section{Probability of cancer risk (CR)}

The cancer risks associated with the use of the water resources were estimated as the incremental threat of an individual developing cancer over a lifetime, resulting from the exposure to a potential carcinogen (Rahman et al. 2017). The CR of each carcinogenic metal is calculated as product of CDI (mg/kg-day) (from Eq. 5) multiplied by the slope factor (SF) (mg/kg/day) (Eq. 12).

$\mathrm{CDI} \times \mathrm{SF}$

An acceptable value is $\leq 1 \times 10^{-6}$, which means, on average, the probability is that approximately 1 per $1,000,000$ will develop cancer as a consequence of the exposure to a carcinogen ( $\mathrm{Lim}$ et al. 2008; Adamu et al. 2014). However, risk in the range of $1 \times 10^{-6}-1 \times 10^{-4}$ typically has been reported to be acceptable (US-EPA 1999; Yang et al. 2012; Rahman et al. 2017; Egbueri 2020a). In calculating the $\mathrm{CR}$ for this study, only $\mathrm{Pb}$ and $\mathrm{Cr}$ concentrations in water were utilized. This was because the SF of
$\mathrm{Ni}$ is not determined (i.e., unknown). $\mathrm{SF}$ values for $\mathrm{Pb}$ and $\mathrm{Cr}$ (carcinogens) used in this study were given as 0.0085 and 0.05 (Naveedullah et al. 2014; Patrick-Iwuanyanwu and Chioma 2017).

\section{Chemometric analysis for pollution source identification and risk assessment}

\section{Correlation analysis (CA), principal component analysis (PCA), and hierarchical cluster analysis (HCA)}

The analyzed water quality and health risk parameters were subjected to Pearson's correlation analysis using the IBM SPSS software (v. 22). This was done to establish the interrelationships between the analyzed parameters (contaminants/pollutants) and their possible sources in the Ojoto Province. Parameters with association (correlation) coefficients $(r)>0.7,0.7>r>0.5$, and $r<0.5$ were considered as strong, moderate, and weak, respectively (Barzegar et al. 2018; Mgbenu and Egbueri 2019). Strong and moderate coefficients also indicate pairs with significant risk factors, while those with weak coefficients indicate low risk factor.

The PCA was also used to study the interrelationships between analyzed parameters and their factor loadings (Egbueri 2018, 2019a, b). The degree of the impact of heavy metals on non-carcinogenic and carcinogenic health risk parameters and WQI was also analyzed using the PCA. The PCA was used to show the parameters (components) with low, medium, and high factor loadings. In addition, it was used to identify the most significant health risk factor (parameter) loadings. Varimax rotation (with Kaiser normalization) was used in extracting the factor components. The exact number of factors was chosen by Kaiser (1958, 1960) criterion in which factors with eigenvalues $<1$ are not considered. In this study, factor loadings above 0.75 were classed as high, those between 0.50 and 0.75 as medium, and those below 0.50 as weak (Tziritis et al. 2017). This was based on the fact that the higher a factor loading of a parameter, the greater its participation to the examined factor group.

The SPSS software (v. 22) was also used to perform the HCA. This statistical tool (HCA) is commonly used in water quality evaluation to group, into the same cluster/class, samples with similar quality, and risk characteristics (Egbueri 2018, 2019a, b, c; Egbueri and Unigwe 2019). In other words, HCA successfully classifies water samples based on their qualities. The Ward's linkage method (with squared Euclidean distance and $\mathrm{z}$-score standardization) was used in this analysis. A dendrogram was produced to show the quality groups of the water samples based on their $\mathrm{pH}$, trace metal contents, WQI, HI, HPI, HEI, and $C_{\mathrm{deg}}$. 


\section{Results and discussion}

\section{lonic and heavy metal concentrations in the waters}

Results of the physicochemical analysis of the water samples are presented in Table 1. Table 2 presents the univariate statistical summary of the physicochemical results and their comparisons with drinking water quality standards (NIS 2007; World Health Organization, WHO 2017). The $\mathrm{pH}$ value varies from 4 to 6.4 which indicates that most of the samples are slightly acidic. pH has no health-based guideline by the NIS (2007) and WHO (2017). However, Ravikumar et al. (2013) and WHO (2017) reported that long-term exposure of aesthetics to acidic water could lead to corrosion effect. Bicarbonate ion concentration ranges from 0 to $5 \mathrm{mg} / \mathrm{L}$, not exceeding the standard maximum permissible limits (NIS 2007; WHO 2017). The low concentration of the bicarbonate ions in the waters suggests low dissolution of atmospheric $\mathrm{CO}_{2}$ in water, low content of soil $\mathrm{CO}_{2}$, and no carbonate rock/mineral dissolution within the study area (Mgbenu and Egbueri 2019). Ca concentrations are below the maximum permissible limits of WHO (2017) and, hence, would neither pose health risks nor lead to water hardening (Egbueri 2019a). The presence of calcium ions in water is linked to the weathering and dissolution of calcium-bearing minerals. Likewise, sodium ion concentration is generally low $(<39 \mathrm{mg} / \mathrm{L})$, indicating minimal weathering of Na-rich minerals. The low concentration of $\mathrm{NO}_{3}$ indicates low inputs from anthropogenic activities (such as the use of organic and NPK-rich fertilizers, and poor sewage disposal) that could lead to high nitrates in water (Egbueri 2018, 2019a, b).

Table 1 The chemical ions and heavy metal concentrations in water samples

\begin{tabular}{|c|c|c|c|c|c|c|c|c|c|c|c|c|c|}
\hline \multirow[t]{2}{*}{ Sample code } & \multirow[t]{2}{*}{ Water source } & \multirow[t]{2}{*}{$\mathrm{pH}$} & \multicolumn{11}{|c|}{ Measured in $\mathrm{mg} / \mathrm{L}$} \\
\hline & & & $\mathrm{Na}^{+}$ & $\mathrm{Ca}^{2+}$ & $\mathrm{Cl}^{-}$ & $\mathrm{SO}_{4}{ }^{2-}$ & $\mathrm{HCO}_{3}^{-}$ & $\mathrm{NO}_{3}^{-}$ & $\mathrm{Fe}$ & $\mathrm{Zn}$ & $\mathrm{Ni}$ & $\mathrm{Cr}$ & $\mathrm{Pb}$ \\
\hline WS05 & Spring & 5.2 & 25 & 7 & 25 & 24 & 0.0 & 0.04 & 3.1 & 0.00 & 0.000 & 0.000 & 1.090 \\
\hline WS14 & Spring & 4.5 & 14 & 6 & 62 & 55 & 0.5 & 0.0 & 0.8 & 0.00 & 0.000 & 0.000 & 0.090 \\
\hline WS15 & Spring & 4.6 & 28 & 23 & 41 & 60 & 0.5 & 0.0 & 0.1 & 0.12 & 0.000 & 0.000 & 0.000 \\
\hline WS23 & Spring & 4.4 & 14 & 6 & 2 & 7 & 0.3 & 0.1 & 0.4 & 0.21 & 0.000 & 0.190 & 0.052 \\
\hline WS27 & Spring & 4.2 & 21 & 4 & 2 & 23 & 0.0 & 0.1 & 1.1 & 0.12 & 0.000 & 0.002 & 0.980 \\
\hline WS01 & Stream & 5.4 & 14 & 8 & 2 & 10 & 1.2 & 0.6 & 0.2 & 0.04 & 0.000 & 0.010 & 0.000 \\
\hline WS02 & Stream & 6.3 & 13 & 13 & 15 & 14 & 4 & 0.0 & 3.6 & 0.54 & 0.140 & 0.002 & 3.087 \\
\hline WS20 & Stream & 5.0 & 30 & 8 & 18 & 64 & 3.2 & 0.4 & 0.5 & 0.00 & 0.000 & 0.000 & 0.000 \\
\hline WS06 & HW & 4.8 & 17 & 8 & 8 & 115 & 3.2 & 0.02 & 0.4 & 0.11 & 0.000 & 0.000 & 0.000 \\
\hline WS12 & HW & 5.1 & 15 & 4 & 3 & 40 & 3.2 & 0.0 & 2.4 & 0.00 & 0.000 & 0.000 & 0.000 \\
\hline WS24 & HW & 4.1 & 20 & 7 & 9 & 130 & 0.6 & 0.03 & 0.0 & 0.11 & 0.000 & 0.000 & 0.000 \\
\hline WS03 & $\mathrm{BH}$ & 5.8 & 15 & 2 & 2 & 70 & 2 & 0.9 & 0.4 & 0.20 & 0.020 & 0.001 & 2.000 \\
\hline WS04 & BH & 4.6 & 13 & 4 & 4 & 10 & 0.0 & 0.0 & 0.4 & 0.03 & 0.000 & 0.000 & 0.021 \\
\hline WS07 & BH & 4.7 & 10 & 20 & 4 & 48 & 0.0 & 0.03 & 0.5 & 0.32 & 0.000 & 0.015 & 0.000 \\
\hline WS08 & $\mathrm{BH}$ & 4.8 & 8 & 8 & 2 & 13 & 0.0 & 1.9 & 0.2 & 0.04 & 0.000 & 0.000 & 0.012 \\
\hline WS09 & BH & 4.8 & 10 & 3 & 21 & 24 & 0.4 & 0.03 & 0.3 & 0.00 & 0.000 & 0.000 & 0.000 \\
\hline WS10 & $\mathrm{BH}$ & 5.9 & 27 & 25 & 20 & 67 & 3.5 & 0.0 & 0.1 & 0.10 & 0.000 & 0.000 & 0.000 \\
\hline WS11 & BH & 4.3 & 15 & 6 & 12 & 8 & 3.2 & 0.2 & 0.1 & 0.06 & 0.000 & 0.000 & 0.061 \\
\hline WS13 & BH & 6.0 & 16 & 11 & 5 & 25 & 2.0 & 0.3 & 0.4 & 0.01 & 0.120 & 0.000 & 0.001 \\
\hline WS16 & BH & 4.0 & 15 & 10 & 3 & 33 & 0.4 & 18.48 & 0.4 & 0.00 & 0.000 & 0.000 & 0.000 \\
\hline WS17 & BH & 5.0 & 17 & 2 & 3 & 18 & 0.0 & 8.4 & 0.3 & 0.00 & 0.000 & 0.000 & 0.000 \\
\hline WS18 & BH & 6.4 & 12 & 8 & 4 & 26 & 3 & 0.06 & 0.4 & 0.01 & 0.120 & 0.000 & 0.001 \\
\hline WS19 & BH & 4.9 & 38 & 4 & 33 & 72 & 5 & 4.2 & 0.1 & 0.40 & 0.340 & 0.004 & 1.980 \\
\hline WS21 & BH & 5.3 & 12 & 3 & 25 & 8 & 0.4 & 1.68 & 0.3 & 0.12 & 0.000 & 0.000 & 0.000 \\
\hline WS22 & $\mathrm{BH}$ & 4.6 & 14 & 3 & 23 & 25 & 0.6 & 0.03 & 0.2 & 0.00 & 0.000 & 0.000 & 0.000 \\
\hline WS25 & $\mathrm{BH}$ & 4.4 & 11 & 5 & 10 & 64 & 0.0 & 1.8 & 0.4 & 0.00 & 0.000 & 0.000 & 0.011 \\
\hline WS26 & $\mathrm{BH}$ & 4.8 & 12 & 7 & 21 & 15 & 0.0 & 14.4 & 0.2 & 0.34 & 0.230 & 0.012 & 1.430 \\
\hline WS28 & BH & 5.4 & 14 & 2 & 3 & 70 & 1.5 & 1.24 & 0.3 & 0.20 & 0.020 & 0.001 & 2.000 \\
\hline
\end{tabular}

Table arranged based on sources of water samples

$B H$ borehole, $H W$ hand-dug well 
Table 2 Statistical summary of chemical ions and heavy metal concentrations compared to quality standards

\begin{tabular}{|c|c|c|c|c|c|c|c|}
\hline Analyzed parameter & Min. & Max. & Mean & SD & WHO (2017) & NIS (2007) & Impact when in excess (NIS 2007; WHO 2017) \\
\hline $\mathrm{pH}$ & 4 & 6.4 & 4.975 & 0.6438 & $6.5-8.5$ & $6.5-8.5$ & Problems related to taste, odor, and color \\
\hline $\mathrm{Na}^{+}(\mathrm{mg} / \mathrm{L})$ & 8 & 38 & 16.786 & 6.9461 & 200 & 200 & No health-based guideline \\
\hline $\mathrm{Ca}^{2+}(\mathrm{mg} / \mathrm{L})$ & 2 & 25 & 7.750 & 5.9791 & 75 & - & No health-based guideline \\
\hline $\mathrm{SO}_{4}^{2-}(\mathrm{mg} / \mathrm{L})$ & 7 & 130 & 40.643 & 32.2343 & 250 & 100 & Undesirable taste \\
\hline $\mathrm{Cl}^{-}(\mathrm{mg} / \mathrm{L})$ & 2 & 62 & 13.643 & 14.3119 & $200-300$ & 250 & Salty taste \\
\hline $\mathrm{HCO}_{3}^{-}(\mathrm{mg} / \mathrm{L})$ & 0 & 5 & 1.382 & 1.5300 & 250 & - & No health-based guideline \\
\hline $\mathrm{NO}_{3}^{-}(\mathrm{mg} / \mathrm{L})$ & 0 & 18.48 & 1.962 & 4.4803 & 50 & 50 & $\begin{array}{l}\text { Methemoglobinemia (blue-baby syndrome); encourages } \\
\text { growth of microorganisms }\end{array}$ \\
\hline $\mathrm{Fe}(\mathrm{mg} / \mathrm{L})$ & 0 & 3.6 & 0.629 & 0.8915 & 0.3 & 0.3 & $\begin{array}{l}\text { No health-based guideline; scaling in pipes; cloth; and } \\
\text { plumbing fixtures discoloration }\end{array}$ \\
\hline $\mathrm{Zn}(\mathrm{mg} / \mathrm{L})$ & 0 & 0.54 & 0.110 & 0.1415 & 4 & 3 & No health-based guideline; undesirable taste \\
\hline $\mathrm{Ni}(\mathrm{mg} / \mathrm{L})$ & 0 & 0.34 & 0.035 & 0.0823 & 0.07 & 0.02 & Carcinogenic and non-carcinogenic health impact \\
\hline $\mathrm{Cr}(\mathrm{mg} / \mathrm{L})$ & 0 & 0.19 & 0.009 & 0.0358 & 0.05 & 0.05 & Carcinogenic and non-carcinogenic health impact \\
\hline $\mathrm{Pb}(\mathrm{mg} / \mathrm{L})$ & 0 & 3.087 & 0.530 & 0.8562 & 0.01 & 0.01 & $\begin{array}{l}\text { Carcinogenic, mental retardation, toxic to nervous systems, } \\
\text { inhibits the metabolism of vitamin D }\end{array}$ \\
\hline
\end{tabular}

The order of dominance of heavy metals in the analyzed samples is $\mathrm{Fe}>\mathrm{Pb}>\mathrm{Zn}>\mathrm{Ni}>\mathrm{Cr}$. Heavy metals' concentrations in the water resources can be linked to land use and natural processes such as mechanic workshops, industrial effluents, poor waste disposal system, weathering, erosion, and leaching (Duggal et al. 2017; Barzegar et al. 2018; Egbueri 2018, 2019a; Egbueri et al. 2019; Mgbenu and Egbueri 2019). In this study, the measured values of $\mathrm{Pb}$ in water show that about $46 \%$ of the water samples are unsafe for human use (NIS 2007; WHO 2017). The high Pb concentrations in these samples may be attributed to lead leaching from plumbing systems and waste disposal sites. Zn concentration is generally low in the samples (Table 2). However, it was observed that $17.85 \%$ and $14.28 \%$ of the total samples, respectively, have $\mathrm{Ni}$ and $\mathrm{Fe}$ concentrations higher than the NIS (2007) and WHO (2017) standard limits. Only sample WS23 had Cr ions concentration higher than standard limit, and this can lead to cancer of the respiratory system (NIS 2007; WHO 2017).

\section{Water quality index (WQI) for drinking purpose}

Table 3 presents the various weights and relative weights assigned to the selected parameters used in the WQI analysis. The final results obtained from the WQI analysis are presented in Table 4. It was observed that $50 \%$ of the samples classified as 'excellent water' for drinking purposes. Nevertheless, only two samples, constituting $7.14 \%$ of the total samples, classified as 'good water.' In total, $25 \%$ of the total samples are unfit for drinking, whereas $10.72 \%$ and $7.14 \%$ of the total samples are in 'poor water' and 'very poor water' categories, respectively. It was also observed that the samples in poor, very poor, and unfit water categories $(42.86 \%$ of the total) are the samples with high heavy
Table 3 Relative weight of selected WQI parameters (Mgbenu and Egbueri 2019)

\begin{tabular}{llll}
\hline Parameter & NIS (2007) & Weight $\left(w_{i}\right)$ & $\begin{array}{l}\text { Relative weight }\left(W_{i}\right) \\
W_{i}=w_{i} / \sum w_{i}(i=1 \text { to } n)\end{array}$ \\
\hline $\mathrm{pH}$ & $6.5-8.5$ & 3 & 0.1364 \\
$\mathrm{Fe}$ & 0.3 & 2 & 0.0909 \\
$\mathrm{Zn}$ & 3 & 2 & 0.0909 \\
$\mathrm{~Pb}$ & 0.01 & 5 & 0.2273 \\
$\mathrm{Ni}$ & 0.02 & 4 & 0.1818 \\
$\mathrm{Cr}$ & 0.05 & 4 & 0.1818 \\
& & $\sum w_{i}=22$ & $\sum W_{i}=0.9091$ \\
\hline
\end{tabular}

metal contents. Being polluted with trace metals, the waters may only serve domestic purposes that do not require them for food processing.

The geospatial distribution based on the WQI classes of the analyzed waters was determined by creating a zonation map for the study area (Fig. 2). This was done to evaluate the spatial extent of water quality for drinking purposes in the study area. From Fig. 2, it can be observed that the area is dominated by two extreme classes, the 'excellent water' and 'unfit for drinking water.' The eastern and northern portions of the study area are dominated by excellent drinking waters than other portions. This could be attributed to differences in the impact of urbanization, land use/industrial activities, and human population. The eastern and northern parts have low rate of urbanization, low industrial activities, and low population. However, the northwestern and southern parts have deteriorated water quality (Fig. 2), and this could be due to the following reasons: (1) They are more urbanized with industries; (2) they have higher population; (3) they have higher volumes of wastes per capita and poor waste 
Table 4 Quality index of the individual water samples

\begin{tabular}{|c|c|c|c|}
\hline Sample code & Water source & WQI & Water quality class \\
\hline WS01 & Stream & 21.15 & Excellent water \\
\hline WS06 & HW & 22.52 & Excellent water \\
\hline WS07 & $\mathrm{BH}$ & 31.43 & Excellent water \\
\hline WS08 & $\mathrm{BH}$ & 43.53 & Excellent water \\
\hline WS09 & $\mathrm{BH}$ & 19.16 & Excellent water \\
\hline WS10 & $\mathrm{BH}$ & 15.41 & Excellent water \\
\hline WS15 & Spring & 13.04 & Excellent water \\
\hline WS16 & $\mathrm{BH}$ & 10.51 & Excellent water \\
\hline WS17 & $\mathrm{BH}$ & 19.58 & Excellent water \\
\hline WS20 & Stream & 25.64 & Excellent water \\
\hline WS21 & $\mathrm{BH}$ & 20.57 & Excellent water \\
\hline WS22 & $\mathrm{BH}$ & 15.71 & Excellent water \\
\hline WS24 & HW & 8.93 & Excellent water \\
\hline WS25 & $\mathrm{BH}$ & 46.35 & Excellent water \\
\hline WS04 & $\mathrm{BH}$ & 87.77 & Good water \\
\hline WS12 & HW & 83.42 & Good water \\
\hline WS11 & $\mathrm{BH}$ & 150.88 & Poor water \\
\hline WS13 & $\mathrm{BH}$ & 136.09 & Poor water \\
\hline WS18 & $\mathrm{BH}$ & 136.93 & Poor water \\
\hline WS14 & Spring & 238.25 & Very poor water \\
\hline WS23 & Spring & 209.55 & Very poor water \\
\hline WS02 & Stream & 7268.67 & Unfit for drinking \\
\hline WS03 & $\mathrm{BH}$ & 4589.44 & Unfit for drinking \\
\hline WS05 & Spring & 2582.38 & Unfit for drinking \\
\hline WS19 & $\mathrm{BH}$ & 4825.57 & Unfit for drinking \\
\hline WS26 & $\mathrm{BH}$ & 3480.98 & Unfit for drinking \\
\hline WS27 & Spring & 2271.40 & Unfit for drinking \\
\hline WS28 & $\mathrm{BH}$ & 4585.57 & Unfit for drinking \\
\hline
\end{tabular}

Table arranged based on quality of samples

$B H$ borehole, $H W$ hand-dug well

management strategies; and (4) they have numerous automobile workshops. According to Egbueri (2018), these characteristics predispose an area to water quality deterioration. It was further observed that sample WS02, a stream water, in the southern part of the study area has the poorest water quality (with the highest WQI value) (Table 4, Fig. 2). Based on field observations, this stream receives the highest volumes of different kinds of wastes than other surface waters.

\section{Human health risk assessments}

\section{Non-carcinogenic health risk assessment}

The HQ and HI from ingestion of trace-metal-contaminated water on humans (adult and children populations) for all the samples are presented in Table 5. Based on the HQ analysis, the order of impact of the trace metals with respect to their mean values is $\mathrm{Pb}>\mathrm{Ni}>\mathrm{Fe}>\mathrm{Zn}>\mathrm{Cr}$ for the children population and $\mathrm{Pb}>\mathrm{Fe}>\mathrm{Ni}>\mathrm{Zn}>\mathrm{Cr}$ for the adult population (Table 5). In both population groups, and by examination of the samples based on their HQ, values $>1$ increase the non-carcinogenic risks of water by ingestion (US-EPA 1989; Bortey-Sam et al. 2015; Su et al. 2017). The HI results show that $25 \%$ of the samples (including WS02, WS03, WS05, WS19, WS26, WS27, and WS28) predispose their users (both adult and children populations) to high noncarcinogenic, chronic risks. The samples' high $\mathrm{HI}$ is attributed to their high $\mathrm{Pb} \mathrm{HQ}$ values. These samples identified in the 'high risk' category are the same samples described in WQI as 'unfit for drinking.' Furthermore, High HI values were observed in drilled well samples (WS03, WS19, WS26, WS28) suspected to be characterized by shallow aquifers (Nfor et al. 2007; Okoro et al. 2010b; Akpoborie et al. 2011). Generally, shallow aquifers, which usually lack confining layers, are easily contaminated by surface processes, thereby deteriorating the groundwater quality (Egbueri 2018, 2019b). Moreover, these samples were collected from parts of the study area where mechanic, industrial, and poor waste disposal activities are relatively intense. However, samples WS09, WS16, WS17, WS20, and WS22 (constituting about $17.86 \%$ of the total samples) have negligible non-carcinogenic risk for both adult and children populations. Other samples' risk levels vary from 'negligible' to 'medium' non-carcinogenic risks from consumption by the adult and children populations (Table 5). Nevertheless, it was observed that none of the hand-dug wells poses medium-high chronic risk to water consumers (both adult and children).

\section{Carcinogenic health risk assessment}

Results of the carcinogenic risk assessments (HPI, HEI, $C_{\mathrm{deg}}$, and CR) were summarized and are presented in Table 6 . For this study, HPI $<20$ indicates safe water quality, whereas HPI $>20$ indicates a critical water quality. Based on the HPI classification, $75 \%$ of the total samples are safe drinking water, whereas $25 \%$ of the samples are not safe for drinking (Table 6). Based on HEI classifications: HEI $<400$ indicates high-quality water, $\mathrm{HEI}=400-800$ indicates medium contamination risk, and HEI $>800$ indicates high contamination risk (Edet and Offiong 2002). All the samples are in the first category and therefore would pose low carcinogenic risk when ingested. However, $C_{\mathrm{deg}}>80$ indicates low-quality water for drinking, while $C_{\mathrm{deg}}<40$ indicates high-quality water (i.e., with low contamination index). In this study, and on the basis of the $C_{\mathrm{deg}}, 21.5 \%$ of the total samples are highly contaminated with heavy metals, whereas $78.5 \%$ of the samples have low contamination index and hence have low potentiality for carcinogenic risk.

Probability of cancer risk (CR) due to $\mathrm{Pb}$ and $\mathrm{Cr}$ contaminations, for both adult and children populations, is also presented in Table 6. Generally, cancer risk in the range

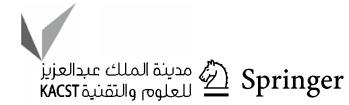




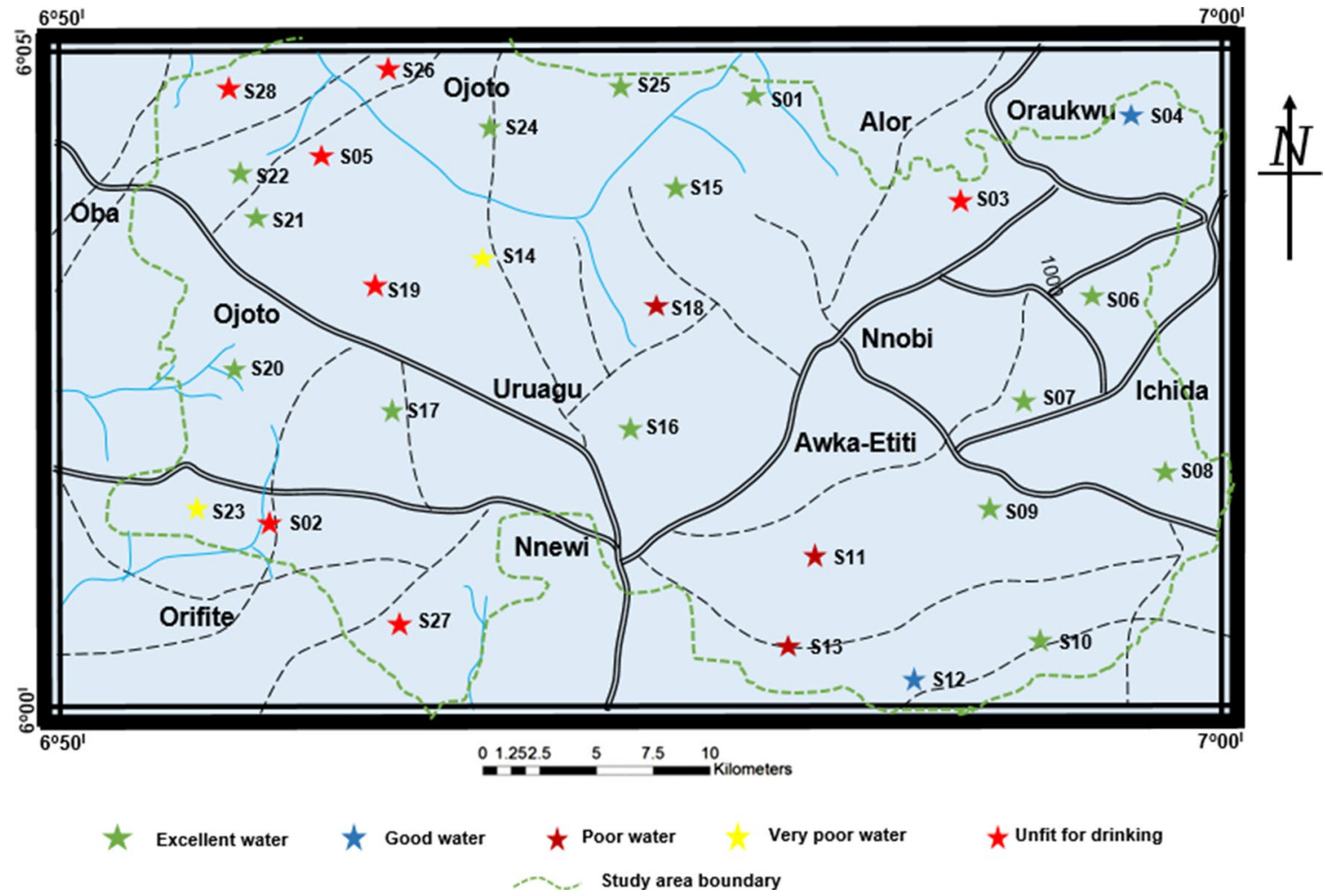

Fig. 2 Spatial distribution of samples' quality based on their WQI

of $\leq 1 \times 10^{-6}-1 \times 10^{-4}$ is acceptable (US-EPA 1999; Lim et al. 2008; Yang et al. 2012; Adamu et al. 2014; Rahman et al. 2017; Egbueri 2020a). The CR results show that eight samples $(28.57 \%$ of the total samples $)$ predispose adult and children to high cancer risk. However, $25 \%$ (7 samples) pose cancer risk due to $\mathrm{Pb}$ contamination, while only $3.57 \%$ (1 sample) predispose the adult and children populations to cancer risk due to $\mathrm{Cr}$ contamination. It was observed that none of the hand-dug wells poses cancer risk to water consumers. The $\mathrm{CR}$ results also revealed that $\mathrm{Pb}$ has the highest risk factor and, thus, identified to be the top priority pollutant in the study area. Therefore, the residents (who consume the contaminated waters without treating) are more predisposed to health risks associated with lead poisoning. The high content of $\mathrm{Pb}$ in the waters can be attributed to sources like plumbing materials, mechanic workshops, industrial activities, and open dumpsites (where automobile spare parts, e.g., batteries and plastics, are also disposed).

\section{Chemometric analysis for pollution source identification and risk assessment}

\section{Correlation analysis (CA)}

The Pearson's correlation matrix (Table 7) was successfully used to show the interrelationships between the analyzed water quality parameters and their possible sources. Table 7 shows that some of the variables have significant positive relationship with one another. However, it was observed that no significant relationship exists between the $\mathrm{pH}$ and all other parameters, except for $\mathrm{HCO}_{3}$. Therefore, $\mathrm{pH}$ is believed to play insignificant role in releasing the analyzed trace metals into the waters (Barzegar et al. 2018). From Table 7, it is observed that Fe has weak correlation with other heavy metals. This indicates differences in origin (sources). Although other heavy metals may be attributed to anthropogenic sources (including mechanic workshops, industrial activities, and open dumpsites), the Fe in water is attributed to weathering processes of iron-bearing minerals in the rocks and soils of the study area. Moreover, research has shown that Fe concentration in water is greatly influenced by redox conditions (Barzegar et al. 2018).

Furthermore, just like the $\mathrm{Fe}, \mathrm{Cr}$ has more of negative associations (and no significant correlation) with the other parameters (including the heavy metals). This could be due to the presence of various pollution sources (Chen et al. 2014; Tziritis et al. 2017; Barzegar et al. 2018; Egbueri 2018, 2019a). Although all the heavy metals (except Fe) were generally classified to have anthropogenic sources, $\mathrm{Cr}$ is thought to have peculiar waste source(s) (with different leachate makeup), different from where other heavy metals $(\mathrm{Zn}, \mathrm{Ni}$, and $\mathrm{Pb})$ were leached from. According to Egbueri 
Table 5 Results of non-carcinogenic health risk assessment (HQ and HI)

\begin{tabular}{|c|c|c|c|c|c|c|}
\hline \multirow{2}{*}{$\begin{array}{l}\mathrm{HI}<0.1 \text { (negligible) } \\
\text { Sample ID }\end{array}$} & \multirow{2}{*}{$\begin{array}{l}\mathrm{HI} \geq 0.1<1 \text { (low) } \\
\text { Source }\end{array}$} & \multirow{2}{*}{$\begin{array}{l}\mathrm{HI} \geq 1<4 \text { (medium) } \\
\text { (HI adult) }\end{array}$} & \multirow{2}{*}{$\begin{array}{l}\mathrm{HI} \geq 4 \text { (high risk) } \\
\text { (HI children) }\end{array}$} & \multicolumn{3}{|c|}{ Statistical summary of HQ for the heavy metals } \\
\hline & & & & Heavy metal & HQ range & HQ mean \\
\hline S05 & Spring & 9.0245 & 21.0571 & Fe (adult) & $0.000-0.147$ & 0.026 \\
\hline $\mathrm{S} 14$ & Spring & 0.7674 & 1.7905 & & & \\
\hline S15 & Spring & 0.0155 & 0.4362 & Fe (children) & $0.000-0.343$ & 0.060 \\
\hline $\mathrm{S} 23$ & Spring & 0.4644 & 1.7837 & & & \\
\hline S27 & Spring & 8.0564 & 19.1982 & Zn (adult) & $0.000-0.051$ & 0.010 \\
\hline S01 & Stream & 0.0122 & 0.1617 & & & \\
\hline S02 & Stream & 25.5984 & 61.0629 & Zn (children) & $0.000-0.120$ & 0.024 \\
\hline S20 & Stream & 0.0204 & 0.0476 & & & \\
\hline S06 & HW & 0.0268 & 0.4292 & Ni (adult) & $0.000-0.486$ & 0.051 \\
\hline $\mathrm{S} 12$ & HW & 0.0980 & 0.2286 & & & \\
\hline S24 & HW & 0.0105 & 0.3911 & Ni (children) & $0.000-1.800$ & 0.367 \\
\hline S03 & BH & 16.3905 & 38.8445 & & & \\
\hline S04 & BH & 0.1906 & 0.5448 & $\mathrm{Cr}$ (adult) & $0.000-0.004$ & 0.000 \\
\hline S07 & BH & 0.0512 & 1.1861 & & & \\
\hline S08 & BH & 0.1099 & 0.3898 & $\mathrm{Cr}$ (children) & $0.000-0.008$ & 0.000 \\
\hline S09 & $\mathrm{BH}$ & 0.0123 & 0.0286 & & & \\
\hline S10 & BH & 0.0136 & 0.3651 & $\mathrm{~Pb}$ (adult) & $0.000-25.200$ & 3.736 \\
\hline S11 & $\mathrm{BH}$ & 0.5078 & 1.3848 & & & \\
\hline S13 & BH & 0.1969 & 0.0927 & $\mathrm{~Pb}$ (children) & $0.000-58.800$ & 8.718 \\
\hline S16 & BH & 0.0163 & 0.0381 & & & \\
\hline S17 & $\mathrm{BH}$ & 0.0122 & 0.0286 & & & \\
\hline S18 & $\mathrm{BH}$ & 0.1969 & 0.0927 & & & \\
\hline S19 & BH & 16.6912 & 39.1462 & & & \\
\hline $\mathrm{S} 21$ & BH & 0.0237 & 0.4552 & & & \\
\hline $\mathrm{S} 22$ & BH & 0.0082 & 0.0191 & & & \\
\hline S25 & $\mathrm{BH}$ & 0.1061 & 0.2476 & & & \\
\hline S26 & BH & 12.0428 & 28.4666 & & & \\
\hline S28 & $\mathrm{BH}$ & 16.3864 & 38.8350 & & & \\
\hline
\end{tabular}

Table arranged based on sources of water samples

(2018) and Mgbenu and Egbueri (2019), Cr in water could be leached from metallurgical waste sources, whereas $\mathrm{Zn}$, $\mathrm{Ni}, \mathrm{Pb}$ could be leached from automobile batteries, tyres, and paints, wires, plumbing, and electronic wastes disposed in dumpsites. The significant correlation between $\mathrm{Zn}$ and $\mathrm{Ni}$, $\mathrm{Zn}$ and $\mathrm{Pb}$, and $\mathrm{Ni}$ and $\mathrm{Pb}$ further indicates that they were derived from the same anthropogenic/leachate sources in the study area. For the current study, the major source of pollution for the heavy metals $(\mathrm{Zn}, \mathrm{Ni}, \mathrm{Cr}, \mathrm{Pb})$-contaminated samples (WS05, WS14, WS19, WS26, and WS28) in the northwestern portion of the study area is strongly linked to a central dumpsite directly opposite the National Metallurgical Institute, Oba, located northwest of the study area.

The trace metals ( $\mathrm{Zn}, \mathrm{Pb}$, and $\mathrm{Ni}$ ) were also observed to have significant association with the WQI, HI, HPI, HEI, and $C_{\text {deg }}$. The correlation matrix establishes the point that these metals are the priority heavy metals (pollutants) deteriorating water quality in the study area. However, $\mathrm{Pb}$ is the top priority pollutant (having strongest association with WQI, HI, HPI, HEI, and $C_{\mathrm{deg}}$ the highest risk factor). Although CR for $\mathrm{Ni}$ in water was not calculated, it is suspected (based on the correlation matrix) that cancer risk due to Ni concentrations could be significant in some of the water samples. Furthermore, perfect correlations were observed among WQI, HI, HPI, HEI, and $C_{\text {deg }}$, indicating strong positive interrelationships between them. It also confirms that the same kind of parameters (trace metals), following a particular trend/ pattern, impacts their significance in this study.

\section{Principal component analysis (PCA)}

In order to establish adequate understanding of the sources of heavy metals and other parameters in the analyzed samples, the PCA is integrated with the CA. Results of the PCA are presented in Table 8 . The significance of the factor loadings is defined at 0.500 . In the present study, six different 
Table 6 Results of carcinogenic health risk of samples

\begin{tabular}{|c|c|c|c|c|c|c|c|c|}
\hline \multirow[t]{2}{*}{ Sample ID } & \multirow[t]{2}{*}{ Water source } & \multirow[t]{2}{*}{ HEI } & \multirow[t]{2}{*}{ HPI } & \multirow[t]{2}{*}{$C_{\mathrm{deg}}$} & \multicolumn{2}{|l|}{ For children } & \multicolumn{2}{|l|}{ For adult } \\
\hline & & & & & $\mathrm{CR}(\mathrm{Pb})$ & $\mathrm{CR}(\mathrm{Cr})$ & $\mathrm{CR}(\mathrm{Pb})$ & $\mathrm{CR}(\mathrm{Cr})$ \\
\hline WS05 & Spring & 119.33 & 23.87 & 114.3 & $6.21 \times 10^{-4}$ & 0.000 & $2.60 \times 10^{-4}$ & 0.000 \\
\hline WS14 & Spring & 11.667 & 2.333 & 6.667 & $5.10 \times 10^{-5}$ & 0.000 & $2.55 \times 10^{-5}$ & 0.000 \\
\hline WS15 & Spring & 0.373 & 0.074 & -4.627 & 0.000 & 0.000 & 0.000 & 0.000 \\
\hline WS23 & Spring & 10.4 & 2.08 & 7.303 & $2.50 \times 10^{-5}$ & $6.50 \times 10^{-4}$ & $8.50 \times 10^{-6}$ & $2.50 \times 10^{-4}$ \\
\hline WS27 & Spring & 101.75 & 20.35 & 99.74 & $5.53 \times 10^{-4}$ & 0.000 & $2.38 \times 10^{-4}$ & 0.000 \\
\hline WS01 & Stream & 0.879 & 0.175 & -4.121 & 0.000 & $5.00 \times 10^{-5}$ & 0.000 & 0.000 \\
\hline WS02 & Stream & 327.920 & 65.58 & 322 & $1.75 \times 10^{-3}$ & 0.000 & $7.48 \times 10^{-4}$ & 0.000 \\
\hline WS20 & Stream & 1.667 & 0.333 & -3.933 & 0.000 & 0.000 & 0.000 & 0.000 \\
\hline WS06 & HW & 1.369 & 0.273 & -3.631 & 0.000 & 0.000 & 0.000 & 0.000 \\
\hline WS12 & HW & 8 & 1.6 & 3 & 0.000 & 0.000 & 0.000 & 0.000 \\
\hline WS24 & HW & 0.0366 & 0.0073 & -4.963 & 0.000 & 0.000 & 0.000 & 0.000 \\
\hline WS03 & $\mathrm{BH}$ & 202.42 & 40.48 & 197.4 & $1.13 \times 10^{-3}$ & 0.000 & $4.85 \times 10^{-4}$ & 0.000 \\
\hline WS04 & $\mathrm{BH}$ & 3.443 & 0.688 & -1.557 & $8.50 \times 10^{-6}$ & 0.000 & $8.50 \times 10^{-6}$ & 0.000 \\
\hline WS07 & $\mathrm{BH}$ & 2.073 & 0.414 & -2.927 & 0.000 & $5.00 \times 10^{-5}$ & 0.000 & 0.000 \\
\hline WS08 & $\mathrm{BH}$ & 1.879 & 0.376 & -3.121 & $8.50 \times 10^{-6}$ & 0.000 & 0.000 & 0.000 \\
\hline WS09 & $\mathrm{BH}$ & 1 & 0.2 & -4 & 0.000 & 0.000 & 0.000 & 0.000 \\
\hline WS10 & $\mathrm{BH}$ & 0.366 & 0.072 & -4.634 & 0.000 & 0.000 & 0.000 & 0.000 \\
\hline WS11 & $\mathrm{BH}$ & 0.353 & 1.29 & 1.453 & $3.40 \times 10^{-5}$ & 0.000 & $1.70 \times 10^{-5}$ & 0.000 \\
\hline WS13 & $\mathrm{BH}$ & 7.436 & 1.492 & 2.436 & 0.000 & 0.000 & 0.000 & 0.000 \\
\hline WS16 & BH & 1.333 & 0.266 & -3.667 & 0.000 & 0.000 & 0.000 & 0.000 \\
\hline WS17 & BH & 1 & 0.2 & -4 & 0.000 & 0.000 & 0.000 & 0.000 \\
\hline WS18 & BH & 7.436 & 1.486 & 2.103 & 0.000 & 0.000 & 0.000 & 0.000 \\
\hline WS19 & $\mathrm{BH}$ & 215.55 & 43.11 & 210.5 & $1.12 \times 10^{-3}$ & 0.000 & $4.85 \times 10^{-4}$ & 0.000 \\
\hline WS 21 & $\mathrm{BH}$ & 1.04 & 0.208 & -3.96 & 0.000 & 0.000 & 0.000 & 0.000 \\
\hline WS22 & $\mathrm{BH}$ & 0.666 & 0.133 & -4.334 & 0.000 & 0.000 & 0.000 & 0.000 \\
\hline WS25 & $\mathrm{BH}$ & 2.433 & 0.486 & -2.567 & $8.50 \times 10^{-6}$ & 0.000 & 0.000 & 0.000 \\
\hline WS26 & $\mathrm{BH}$ & 155.99 & 31.24 & 150.9 & $8.08 \times 10^{-4}$ & $5.00 \times 10^{-5}$ & $3.49 \times 10^{-4}$ & 0.000 \\
\hline WS28 & $\mathrm{BH}$ & 202.17 & 40.43 & 197.16 & $1.13 \times 10^{-3}$ & 0.000 & $4.85 \times 10^{-4}$ & 0.000 \\
\hline
\end{tabular}

Samples with CR values in bold predispose water users to carcinogenic risk. Table arranged based on sources of water samples factor groups were identified. Their total variances were explained at $86.416 \%$. Principal component (PC) 1 has a variability of $45.881 \%$ with significant loadings of $\mathrm{Zn}, \mathrm{Ni}$, $\mathrm{Pb}, \mathrm{WQI}, \mathrm{HI}, \mathrm{HEI}, \mathrm{HPI}$, and $C_{\mathrm{deg}}$. This is a factor class for the variables with very significant associations in the correlation matrix. The PC 1 accounts for the major pollutants in the study area, with their sources attributed to anthropogenic inputs such as industrial, mechanic, and waste disposal activities. Also, PCA indicated that $\mathrm{Zn}, \mathrm{Ni}$, and $\mathrm{Pb}$ are the major parameters influencing the water quality and health risks. PC 2 explains $9.735 \%$ of the total variance, with significant loading of $\mathrm{pH}(0.810)$ and $\mathrm{HCO}_{3}(0.720)$. Concentration of $\mathrm{HCO}_{3}$ ion in the water is suggestive of influence from natural processes like $\mathrm{CO}_{2}$ dissolution in water (Egbueri 2019a). Moreover, research has shown that change in $\mathrm{pH}$ of water can influence the conversion of dissolved $\mathrm{CO}_{2}$ to bicarbonate ion (McDonald 2006). In PC 3, $\mathrm{Na}(0.605)$ and $\mathrm{SO}_{4}(0.882)$ have significant loading, explaining $8.812 \%$ variability. This factor group is indicative of geogenic origin. However, based on the geology of the study area, there are no deposits of rocks like halite, gypsum, and anhydrites (Reyment 1965, Kogbe 1976; Arua 1986; Nwajide 2013) that could release sodium and sulfate in the water. Therefore, their origin in water could be attributed to natural geogenic processes such as weathering of Na-rich silicate minerals (e.g., feldspars) and oxidation of sulfide in soil (to form sulfate).

PC 4 explains $7.822 \%$ of the variance and has significant loadings of $\mathrm{Na}, \mathrm{Ca}$, and $\mathrm{Cl}$. The sources of these chemical variables are linked to weathering of silicate minerals in the soils and rocks of the study area (Tziritis et al. 2017; Mgbenu and Egbueri 2019). In PC 5 (which explains $7.561 \%$ variability), $\mathrm{NO}_{3}, \mathrm{Fe}$, and $\mathrm{Ni}$ have significant loadings $(0.838,-0.508$, and 0.563 , respectively). However, $\mathrm{Fe}$ recorded negative loading, suggesting it has a different origin from the $\mathrm{NO}_{3}$ and Ni. Fe in the water resources is attributed to geogenic, natural processes such as the weathering 


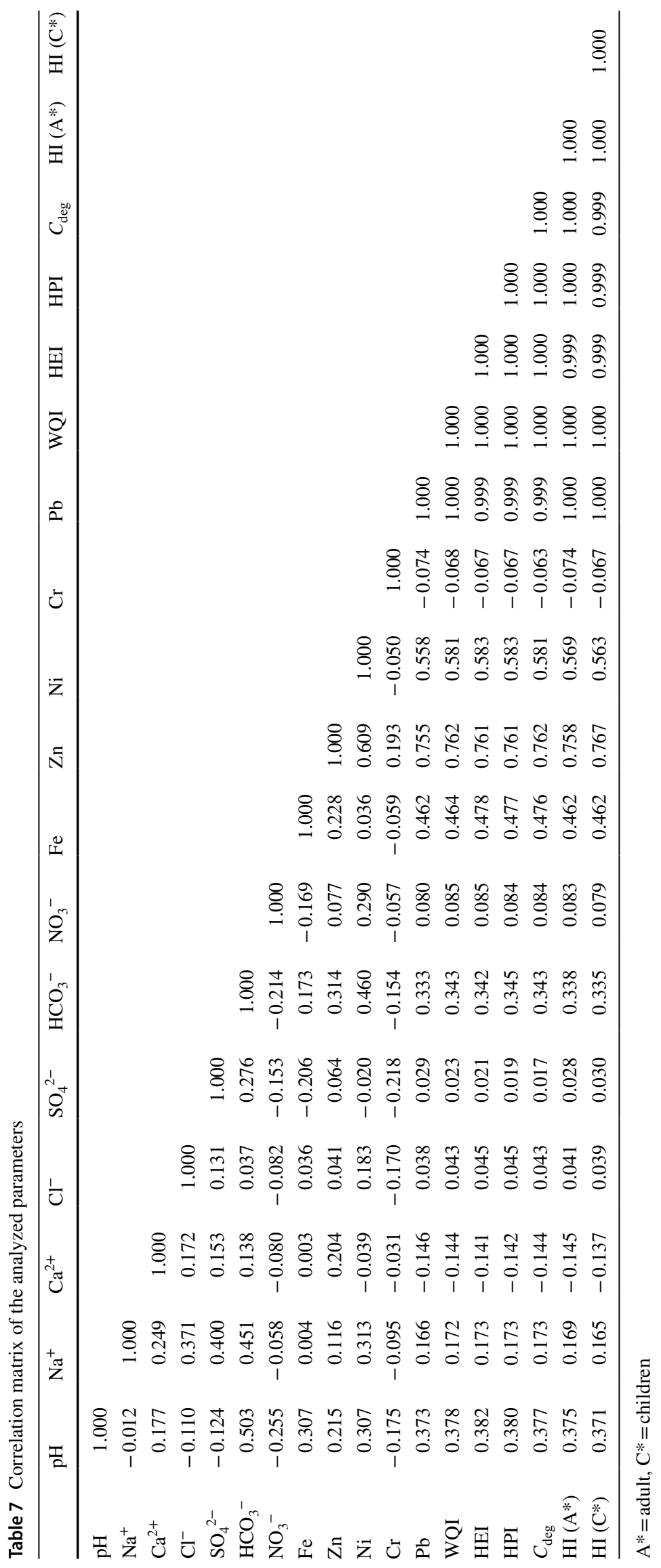


Table 8 The PCA loadings, communalities, and variances (varimax rotated with Kaiser normalization)

\begin{tabular}{|c|c|c|c|c|c|c|c|}
\hline \multirow[t]{2}{*}{ Quality parameter } & \multirow{2}{*}{$\begin{array}{l}\text { Communality } \\
\text { (initial at } 1.00 \text { ) }\end{array}$} & \multicolumn{6}{|c|}{ Principal components (initial eigenvalue $=1$ ) } \\
\hline & & PC 1 & PC 2 & PC 3 & $\mathrm{PC} 4$ & PC 5 & PC 6 \\
\hline $\mathrm{pH}$ & 0.852 & 0.293 & 0.810 & -0.206 & -0.088 & -0.180 & -0.167 \\
\hline $\mathrm{Na}^{+}$ & 0.679 & 0.144 & 0.163 & 0.605 & 0.511 & 0.062 & -0.033 \\
\hline $\mathrm{Ca}^{2+}$ & 0.684 & -0.201 & 0.452 & 0.011 & 0.596 & -0.032 & 0.287 \\
\hline $\mathrm{Cl}^{-}$ & 0.789 & 0.062 & -0.189 & 0.110 & 0.833 & -0.017 & -0.208 \\
\hline $\mathrm{SO}_{4}^{2-}$ & 0.802 & 0.006 & -0.024 & 0.882 & 0.048 & -0.112 & -0.090 \\
\hline $\mathrm{HCO}_{3}{ }^{-}$ & 0.779 & 0.277 & 0.720 & 0.417 & 0.038 & -0.038 & -0.083 \\
\hline $\mathrm{NO}_{3}^{-}$ & 0.805 & 0.088 & -0.222 & -0.193 & -0.018 & 0.838 & -0.092 \\
\hline $\mathrm{Fe}$ & 0.714 & 0.499 & 0.090 & -0.384 & 0.171 & -0.508 & -0.150 \\
\hline $\mathrm{Zn}$ & 0.850 & 0.765 & 0.191 & 0.065 & 0.143 & 0.165 & 0.418 \\
\hline $\mathrm{Ni}$ & 0.787 & 0.555 & 0.356 & 0.102 & 0.159 & 0.563 & 0.014 \\
\hline $\mathrm{Cr}$ & 0.853 & -0.013 & -0.150 & -0.108 & -0.105 & -0.058 & 0.897 \\
\hline $\mathrm{Pb}$ & 0.992 & 0.991 & 0.090 & 0.025 & -0.012 & 0.011 & -0.039 \\
\hline WQI & 0.995 & 0.991 & 0.101 & 0.022 & -0.004 & 0.023 & -0.034 \\
\hline HEI & 0.996 & 0.992 & 0.104 & 0.015 & 0.001 & 0.019 & -0.034 \\
\hline HPI & 0.996 & 0.992 & 0.104 & 0.015 & 0.001 & 0.020 & -0.035 \\
\hline$C_{\mathrm{deg}}$ & 0.996 & 0.992 & 0.101 & 0.015 & 0.000 & 0.019 & -0.031 \\
\hline $\mathrm{HI}\left(\mathrm{A}^{*}\right)$ & 0.993 & 0.991 & 0.095 & 0.024 & -0.008 & 0.017 & -0.039 \\
\hline \multirow[t]{4}{*}{ HI (C*) } & 0.993 & 0.991 & 0.094 & 0.024 & -0.007 & 0.013 & -0.027 \\
\hline & Total & 8.259 & 1.752 & 1.586 & 1.408 & 1.361 & 1.189 \\
\hline & $\%$ variance & 45.881 & 9.735 & 8.812 & 7.822 & 7.561 & 6.605 \\
\hline & Cumulative \% & 45.881 & 55.616 & 64.429 & 72.250 & 79.811 & 86.416 \\
\hline
\end{tabular}

$\mathrm{A}^{*}=$ adult $; \mathrm{C}^{*}=$ children of iron-rich, ferruginous soils, and rocks (e.g., ironstones) in the study area. Contrarily, the $\mathrm{Ni}$ and $\mathrm{NO}_{3}$ may be attributed to local anthropogenic inputs from dumpsites and poor sewage disposal (from residential, industrial, and agricultural activities), respectively (Egbueri 2018, 2019a, b). Comparing the human health risk assessment and the statistical analysis, it can be deduced that although Fe has different origins from other heavy metals, it moderately influences the water quality in this province. This assertion follows its impactful values in the calculation of the various quality indices, its correlation strengths with $\mathrm{Zn}, \mathrm{Pb}$, WQI, HI, HEI, HPI, and $C_{\text {deg }}$, and its loading strengths in PC 1 and PC 5. Finally, PC 6 has strong factor loading (0.897) of Cr. Although most of the samples have very low $\mathrm{Cr}$ concentrations, its cancer risk was high in WS23, a spring sample commonly used by local residents. Based on the geology of the study area, no rock source (such as ultrabasic formations) that could release $\mathrm{Cr}$ is reported. Hence, $\mathrm{Cr}$ origin is attributed to inputs from human activities like industry, agriculture, and landfills (Egbueri 2018).

\section{Hierarchical cluster analysis (HCA)}

HCA was used to classify the water samples, and the resulting dendrogram is presented in Fig. 3. Two major clusters were identified, each cluster with $50 \%$ of analyzed samples.
The first cluster consists of poor quality water samples (2, $28,19,26,2,27,5,14,23,12,13,18,4$, and 11) with the following characteristics: (1) Their WQI classes ranged from 'good water' to 'unsuitable for drinking'; (2) with respect to HI analysis, they are samples with medium to high chronic risk; and (3) on the basis of carcinogenic health risk, they predispose water consumers to medium to high cancer risk. These samples (water sources) are identified as the most vulnerable to contamination by anthropogenic activities. Nevertheless, differences in depths, geology, and land use (anthropogenic activities) have been identified as some factors influencing the pollution of water systems in the study area. It has been indicated in this study that some drilled boreholes (WS03, WS19, WS26, WS28) are shallow based on the reports of previous workers (Nfor et al. 2007; Okoro et al. 2010b; Akpoborie et al. 2011). High heavy metals pollution in these borehole samples suggests that (similar to the contaminated springs and stream) they are also vulnerable to surface contamination processes. Furthermore, although the geology of the study area has been described to have alternating friable sands, shales, sandy shales, and fine-grained fossiliferous sandstones (a scenario whereby aquifer compartmentalization is expected), it is inferred that these shallow boreholes lack confining layers.

The second cluster has the following water samples, which are suitable for consumption by both adult and 
Fig. 3 A dendrogram grouping water samples with respect to their heavy metal contents, WQI, HI (adult and children), HPI, HEI, and $C_{\mathrm{deg}}$

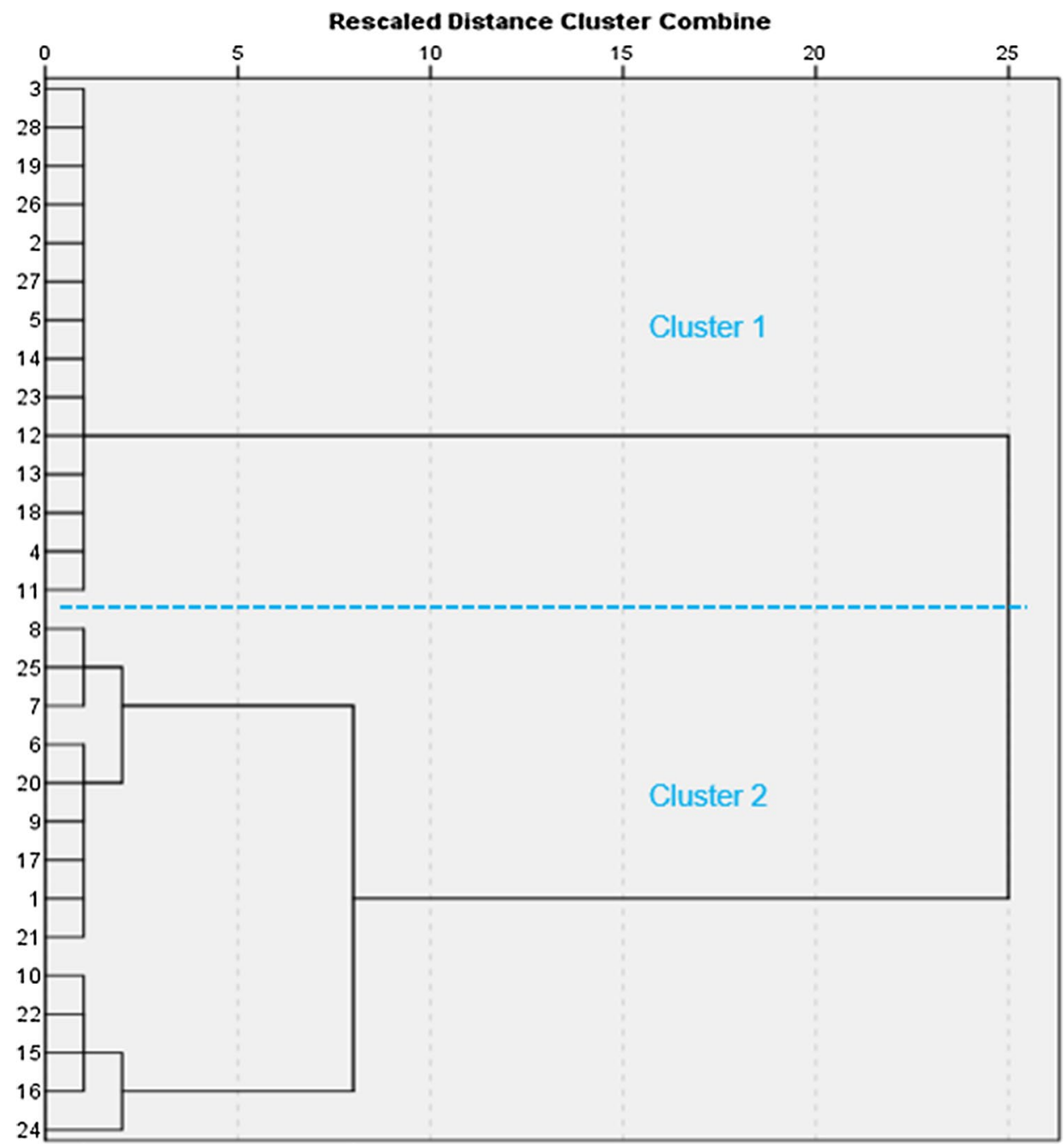

children populations: $8,25,7,6,20,9,17,1,21,10,22$, 15,16 , and 24 . These samples have peculiar characteristics such as: (1) They are described in WQI as desirable excellent drinking water; (2) based on $\mathrm{HI}$ assessment, they would pose low to negligible chronic risk to consumers; and (3) carcinogenic health risk assessment revealed that they are best suited for human consumption and will pose low to negligible cancer risk. The geospatial analysis (Fig. 2) revealed that unsuitable water quality is predominant in the southern and northwestern parts of the study area due to relatively intense anthropogenic activities. However, a stream (WS20) and boreholes $(9,10,16,17$, 21 , and 22) samples were classified as excellent drinking water. Their low level of contamination may be attributed to: (1) low amount of waste disposed into the stream, compared to stream sample WS02; and (2) the boreholes' aquifer being at deeper depth or having confining layers that could inhibit migration of pollutants into the wells.

\section{Conclusions}

This paper has evaluated the chemical constituents, possible pollution sources, quality index, and human health risks (non-carcinogenic and carcinogenic) of water resources in Ojoto Province, southeastern Nigeria. Generally, chemical ions in the waters are within the acceptable limits of the WHO (2017) and NIS (2007). However, some water resources in the study area are subject to different degrees of heavy metals contamination; hence, long-term exposure can pose health risks to residents of the Ojoto Province. Based on the WQI, 50\% and 7.14\% of the total samples classed as excellent and good waters, respectively. Other samples are either in 'poor,' 'very poor,' or 'unfit for use' categories. On the basis of the WQI, it was observed that the northwestern and southern parts of the study area have more of deteriorated water quality. The HI revealed 
that $25 \%$ of the samples predispose their users (both adult and children populations) to high chronic health risks. Moreover, HPI, $C_{\text {deg }}$, and CR revealed that about $25 \%$ of the total samples were unsuitable and off the CR standard acceptable range of $\leq 1 \times 10^{-6}-1 \times 10^{-4}$. However, this study indicated that none of the hand-dug wells poses medium or high chronic and cancer risks to water consumers. The various assessments revealed that $\mathrm{Pb}$ is the priority pollutant impacting the water quality and consequently increasing the human health risks.

The chemometric analyses successfully aided the identification of the possible sources of the water pollutants and the classification of the water resources. Correlation and component factor analyses linked the origin of major ions to geogenic processes and that of the heavy metals to both natural and anthropogenic processes. Based on their peculiar characteristics, the cluster analysis divided the samples into two equal classes (50\% each): poor quality waters and excellent quality waters. Based on the gross characteristics of the different analyzed sources of drinking water in Ojoto Province, the surface waters (springs and streams) and shallow wells are more vulnerable to contamination and pose more health risks than hand-dug wells and deeper boreholes. In other words, the hand-dug wells and deeper boreholes are the least contaminated and hence best suited for consumption by both adult and children populations.

With regard to the water pollution and health risks of the study province, the following recommendations are given for water quality and risk management/control:

1. Residents, policy makers, and governments in the study area should embrace adequate sanitation strategies and regular (temporal) water pollution and quality monitoring over the seasons.

2. Residents should avoid shallow aquifer and drill deeper for aquifer sources that are better insulated from surface processes and contamination.

3. Proper construction of wells to seal off surface contaminants (and thereby protecting groundwater) should be embraced.

4. Public enlightenment campaigns and warnings are essential for sustainable water quality and human health risk management in the area. Instant action is recommended to protect the general public health from serious drinking water pollution problem in the Ojoto Province.

5. Contaminated water should be treated before use. Methods like reverse osmosis, activated carbon filtration, and distillation could be employed, to ensure public health sustainability.

6. This paper is a baseline study and was based on data from 28 water samples and could be expanded (using more sophisticated approaches such as microbiological analysis, lithology geochemical analysis, redox poten- tial analysis, and their roles in enhancing the release of heavy metals in water, etc.) in the future by collecting more samples across the study area. There is also need for a regional study approach/design, for effective pollution monitoring and control plans.

\section{Compliance with ethical standards}

Conflict of interest The authors declare that there is no conflict of interest regarding this paper.

Open Access This article is licensed under a Creative Commons Attribution 4.0 International License, which permits use, sharing, adaptation, distribution and reproduction in any medium or format, as long as you give appropriate credit to the original author(s) and the source, provide a link to the Creative Commons licence, and indicate if changes were made. The images or other third party material in this article are included in the article's Creative Commons licence, unless indicated otherwise in a credit line to the material. If material is not included in the article's Creative Commons licence and your intended use is not permitted by statutory regulation or exceeds the permitted use, you will need to obtain permission directly from the copyright holder. To view a copy of this licence, visit http://creativecommons.org/licenses/by/4.0/.

\section{References}

Adamu CI, Nganje TN, Edet A (2014) Heavy metal contamination and health risk assessment associated with abandoned barite mines in Cross River State, southeastern Nigeria. Nanotechnol Monit Manag, Environ. https://doi.org/10.1016/j.enmm.2014.11.001

Akpoborie IA, Nfor BN, Etobro AAI, Odagwe S (2011) Aspects of the geology and groundwater conditions of Asaba, Nigeria. Arch Appl Sci Res 3(2):537-550

Al-Ami MY, Al-Nakib SM, Ritha NM, Nouri AM, Al-Assina A (1987) Water quality index applied to the classification and zoning of Al-Jaysh canal, Bagdad, Iraq. J Environ Sci Health Part A 22:305-319

APHA (2005) Standard Methods for examination of water and wastewater, 21st edn. American Public Health Association, Washington

Arua I (1986) Paleoenvironment of Eocene deposits in the Afikpo syncline, southern Nigeria. J Afr Earth Sci 5:279-284

Barzegar R, Moghaddam AA, Adamowski J, Nazemi AM (2018) Assessing the potential origins and human health risks of trace elements in groundwater: a case study in the Khoy plain, Iran. Environ Geochem Health. https://doi.org/10.1007/s1065 3-018-0194-9

Belkhiri L, Mouni L, Narany TS, Tiri A (2017) Evaluation of potential health risk of heavy metals in groundwater using the integration of indicator kriging and multivariate statistical methods. Groundw Sustain Dev 4:12-22

Bhuiyan MA, Islam MA, Dampare SB, Parvez L, Suzuki S (2010) Evaluation of hazardous metal pollution in irrigation and drinking water systems in the vicinity of a coal mine area of northwestern Bangladesh. J Hazard Mater 179(1-3):1065-1077

Bortey-Sam N, Nakayama SM, Ikenaka Y, Akoto O, Baidoo E, Mizukawa H, Ishizuka M (2015) Health risk assessment of heavy metals and metalloid in drinking water from communities near gold mines in Tarkwa, Ghana. Environ Monit Assess 187(7):397 
Brown RM, McClelland NI, Deininger RA, Tozer RG (1970) A water quality index: do we dare. Water Sewage Works 117(10):339-343

Chen H, Lu X, Li LY (2014) Spatial distribution and risk assessment of metals in dust based on samples from nursery and primary schools of Xi' an, China. Atmos Environ 88:172-182

Duggal V, Rani A, Mehra R, Balaram V (2017) Risk assessment of metals from groundwater in northeast Rajasthan. J Geol Soc India 90(1):77-84

Edet AE, Offiong OE (2002) Evaluation of water quality pollution indices for heavy metal contamination monitoring: a study case from Akpabuyo-Odukpani area, Lower Cross River Basin (southeastern Nigeria). Geoj 57:295-304. https://doi. org/10.1023/B:GEJO.0000007250.92458.de

Egbueri JC (2018) Assessment of the quality of groundwaters proximal to dumpsites in Awka and Nnewi metropolises: a comparative approach. Int J Energ Water Res. https://doi.org/10.1007/ s42108-018-0004-1

Egbueri JC (2019a) Water quality appraisal of selected farm provinces using integrated hydrogeochemical, multivariate statistical, and microbiological technique. Model Earth Syst Environ. https://doi.org/10.1007/s40808-019-00585-z

Egbueri JC (2019b) Evaluation and characterization of the groundwater quality and hydrogeochemistry of Ogbaru farming district in southeastern Nigeria. SN Appl Sci. https://doi.org/10.1007/ s42452-019-0853-1

Egbueri JC (2019c) Groundwater quality assessment using pollution index of groundwater (PIG), ecological risk index (ERI) and hierarchical cluster analysis (HCA): a case study. Groundw Sustain Dev. https://doi.org/10.1016/j.gsd.2019.100292

Egbueri JC (2020a) Heavy metals pollution source identification and probabilistic health risk assessment of shallow groundwater in Onitsha. Anal Lett, Nigeria. https://doi.org/10.1080/00032 719.2020 .1712606

Egbueri JC (2020b) Signatures of contamination, corrosivity and scaling in natural waters from a fast-developing suburb (Nigeria): insights into their suitability for industrial purposes. Environ Dev Sustain. https://doi.org/10.1007/s10668-020-00597-1

Egbueri JC, Unigwe CO (2019) An integrated indexical investigation of selected heavy metals in drinking water resources from a coastal plain aquifer in Nigeria. SN Appl Sci. https://doi. org/10.1007/s42452-019-1489-x

Egbueri JC, Mgbenu CN, Chukwu CN (2019) Investigating the hydrogeochemical processes and quality of water resources in Ojoto and environs using integrated classical methods. Model Earth Syst Environ. https://doi.org/10.1007/s40808-019-00613 $-y$

Ezugwu CK, Onwuka OS, Egbueri JC, Unigwe CO, Ayejoto DA (2019) Multi-criteria approach to water quality and health risk assessments in a rural agricultural province, southeast Nigeria. HydroResearch. https://doi.org/10.1016/j.hydres.2019.11.005

Herojeet R, Rishi MS, Kishore N (2015) Integrated approach of heavy metal pollution indices and complexity quantification using chemometric models in the Sirsa Basin, Nalagarh valley, Himachal Pradesh, India. Chin J Geochem 34(4):620-633

Horton RK (1965) An index number system for rating water quality. J Wat Pollut Control Fed 37(3):300-305

Kaiser HF (1958) The varimax criterion for analytic rotation in factor analysis. Psychometrika 23(3):187-200

Kaiser HF (1960) The application of electronic computers to factor analysis. Educ Psychol Meas 20:141-151

Kogbe CA (1976) Paleographic history of Nigeria from Albian Times. In: Kogbe CA (ed) Geology of Nigeria. Elizabethan Publishers, Lagos

Lim HS, Lee JS, Chon HT, Sager M (2008) Heavy metal contamination and health risk assessment in the vicinity of the abandoned Songcheon Au-Ag mine in Korea. J Geochem Explor 96:223-230
McDonald J (2006) Alkalinity \& pH relationships. CSTN, pp 392-394

Mgbenu CN, Egbueri JC (2019) The hydrogeochemical signatures, quality indices and health risk assessment of water resources in Umunya district, southeast Nigeria. Appl Water Sci 9(1):22. https ://doi.org/10.1007/s13201-019-0900-5

Musa OK, Shaibu MM, Kudamnya EA (2013) Heavy metal concentration in groundwater around Obajana and its environs, Kogi State, North Central Nigeria. Am Int J Contemp Res 3(8):170-177

Naveedullah M, Hashmi Z, Yu C, Shen H, Duan D, Shen C, Lou L, Chen Y (2014) Concentrations and human health risk assessment of selected heavy metals in surface water of the siling reservoir watershed in Zhejiang Province, China. Pol J Environ Stud 23(3):801-811

Nfor BN, Olobaniyi SB, Ogala JE (2007) Extent and distribution of groundwater resources in parts of Anambra State, Southeastern Nigeria. J Appl Sci Environ Manag 11(2):215-221

NIS (Nigerian Industrial Standard) (2007) Nigerian standard for drinking water quality. Nigerian Industrial Standard, 554, pp 13-14

Njinga RL, Tshivhase VM (2017) Major chemical carcinogens in drinking water sources: health implications due to illegal gold mining activities in Zamfara State, Nigeria. Expo Health. https:// doi.org/10.1007/s12403-017-0265-7

Nwachukwu SO (1972) The tectonic evolution of the southern portion of the Benue Trough, Nigeria. Geol Mag 109:411-419

Nwajide CS (2013) Geology of Nigeria's sedimentary basins. CSS Press, Lagos

Obi GC, Okogbue CO, Nwajide CS (2001) Evolution of the Enugu Cuesta: a tectonically driven erosional process. Glob J Pure Appl Sci 7:321-330

Odukoya AM, Abimbola AF (2010) Contamination assessment of surface and groundwater within and around two dumpsites. Int $\mathbf{J}$ Environ Sci Technol 7(2):367-376

Okoro EI, Egboka BCE, Anike OL, Enekwechi EK (2010a) Evaluation of Groundwater Potentials in parts of the Escarpment area of Southeastern Nigeria. Int J Geomat Geosci 1(3):544-551

Okoro EI, Egboka BCE, Onwuemesi AG (2010b) Evaluation of the aquifer characteristics of the Nanka Sand using hydrogeological method in combination with vertical electric sounding (VES). J Appl Sci Environ Manag 14(2):5-9

Patrick-Iwuanyanwu K, Chioma NC (2017) Evaluation of heavy metals content and human health risk assessment via consumption of vegetables from selected markets in Bayelsa State, Nigeria. Biochem Anal Biochem 6:332. https://doi.org/10.4172/21611009.1000332

Rahman MM, Islam MA, Bodrud-Doza M, Muhib MI, Zahid A, Shammi M, Tareq SM, Kurasaki M (2017) Spatio-temporal assessment of groundwater quality and human health risk: a case study in Gopalganj, Bangladesh. Expo Health. https://doi. org/10.1007/s12403-017-0253-y

Ravikumar P, Aneesul MM, Somashekar RK (2013) Water quality index to determine the surface water quality of Sankey Tank and Mallathahalli Lake, Bangalore Urban District, Karnataka, India. Appl Water Sci 3:247-261

Reyment RA (1965) Aspects of the geology of Nigeria: the stratigraphy of the Cretaceous and Cenozoic deposits. Ibadan University Press, Ibadan

Sridharan M, Nathan DS (2018) Chemometric tool to study the mechanism of arsenic contamination in groundwater of Puducherry Region, South East Coast of India. Chemosphere. https://doi. org/10.1016/j.chemosphere.2018.05.083

Su H, Kang W, Xu Y, Wang J (2017) Assessing groundwater quality and health risks of nitrogen pollution in the Shenfu mining area of Shaanxi Province. Expo Health, Northwest China. https://doi. org/10.1007/s12403-017-0247-9 
Sun L, Peng W, Cheng C (2016) Source estimating of heavy metals in shallow groundwater based on UNMIX. Model: a case study. Indian J Geo-Mar Sci 45(6):756-762

Tziritis EP, Datta PS, Barzegar R (2017) Characterization and assessment of groundwater resources in a complex hydrological basin of central Greece (Kopaida basin) with the joint use of hydrogeochemical analysis, multivariate statistics and stable isotopes. Aquat Geochem. https://doi.org/10.1007/s10498-017-9322-x

Ukah BU, Egbueri JC, Unigwe CO, Ubido OE (2019) Extent of heavy metals pollution and health risk assessment of groundwater in a densely populated industrial area, Lagos, Nigeria. Int J Energ Water Res. https://doi.org/10.1007/s42108-019-00039-3

US-EPA (US Environmental Protection Agency) (1989) Risk assessment guidance for superfund, vol 1, Human health evaluation manual (Part A). Office of Emergency and Remedial Response, Washington

US-EPA (US Environmental Protection Agency) (1999) A risk assessment-multi way exposure spread sheet calculation tool. United States Environmental Protection Agency, Washington

US-EPA (US Environmental Protection Agency) (2011) Exposure factors handbook, 2011 edn (Final Report). EPA/600/R-09/052F. Washington DC

US-EPA (US Environmental Protection Agency) (2017) National recommended water quality criteria - aquatic life criteria table and human health criteria table
Wagh VM, Panaskar DB, Mukate SV, Gaikwad SK, Muley AA, Varade AM (2018) Health risk assessment of heavy metal contamination in groundwater of Kadava River Basin, Nashik, India. Model Earth Syst Environ. https://doi.org/10.1007/s40808-018-0496-z

WHO (2017) Guidelines for drinking water quality, 3rd edn. World Health Organization, Geneva

Yang M, Fei Y, Ju Y, LiH MZ (2012) Health risk assessment of groundwater pollution - a case study of typical City in North China Plain. J Earth Sci 23(3):335-348. https://doi.org/10.1007/s1258 3-012-0260-7

Zhang Y, Wu J, Xu B (2018) Human health risk assessment of groundwater nitrogen pollution in Jinghui canal irrigation area of the loess region, northwest China. Environ Earth Sci 77(7):273. https ://doi.org/10.1007/s12665-018-7456-9

Zhu L, Yang M, Chen X, Liu J (2017) Health risk assessment and risk control: drinking groundwater in Yinchuan Plain. Expo Health, China. https://doi.org/10.1007/s12403-017-0266-6

Publisher's Note Springer Nature remains neutral with regard to jurisdictional claims in published maps and institutional affiliations. 